\title{
Effects of three pesticides on the avoidance behavior of earthworms in laboratory tests performed under temperate and tropical conditions
}

\author{
Marcos Garcia ${ }^{a}$, Jörg Römbke ${ }^{\mathrm{b}, *}$, Marcus Torres de Brito ${ }^{\mathrm{c}}$, Adam Scheffczyk ${ }^{\mathrm{b}}$ \\ ${ }^{\text {a }}$ Embrapa Amazônia Ocidental, Rod. AM-10, Km 28, 69.011-970 Manaus, Brazil \\ ${ }^{\mathrm{b}}$ ECT Oekotoxikologie, Böttgerstr. 2-14, D-65439 Flörsheim, Germany \\ ${ }^{\mathrm{c}}$ CNPq - PIBIC/Embrapa, Rod. AM-10, Km 28, 69.011-970 Manaus, Brazil
}

Received 2 March 2007; received in revised form 1 August 2007; accepted 5 August 2007

The earthworm avoidance test is a practical and sensitive screening method for assessing the effects of pesticides in tropical soils.

\begin{abstract}
Little research has been performed on the impact of pesticides on earthworms under tropical conditions. Taking into consideration the oftenlimited resources in tropical countries, simple screening tests are needed. Therefore, it was investigated whether three pesticides relevant for the Brazilian Amazon (benomyl, carbendazim, lambda-cyhalothrin) affect the avoidance behavior of the earthworm Eisenia fetida. The tests were performed for two days according to ISO guideline 17512 but were adapted to tropical conditions (i.e. test substrate, test organism and temperature). The results indicate that this test gives reproducible and reliable results. Toxicity values (NOEC, EC50) are lower than those determined in 14 day-acute mortality tests and are approximately in the same range such as those found in 56 day-chronic reproduction tests with the same earthworm species, which were performed in parallel. Therefore, the use of the earthworm avoidance tests is recommended as a screening tool for the risk assessment of pesticides.
\end{abstract}

(C) 2007 Elsevier Ltd. All rights reserved.

Keywords: Fungicide; Insecticide; Risk assessment; Artificial soil; Natural soil

\section{Introduction}

Despite the great development of ecotoxicology in previous decades, little research has been performed on the impact of pesticides on tropical ecosystems, considering the amount of studies already conducted in temperate regions. In particular, data on the effects of agricultural chemicals on tropical soil invertebrates are scarce (e.g., Helling et al., 2000). Despite the fact that the fate of these chemicals (and thus the exposure of organisms) may differ in different ecosystems (Klein, 1989; Laabs et al., 2002), practically no effect tests have been performed in Latin America in general or in Brazil in

\footnotetext{
* Corresponding author. Tel.: +49 6145 956450; fax: +49 6145956499.

E-mail address: j-roembke@ect.de (J. Römbke).
}

particular. In fact, most of the data used in the risk assessment of pesticides in tropical countries are generated in North America or Europe (i.e., where temperate species were used). Consequently, an extrapolation of temperate data to tropical conditions without a scientific basis can lead to erroneous results. This study was conducted to establish experimental data that could contribute to the development of such scientific basis for tropical soil ecotoxicology.

The Earthworm Avoidance Test, originally developed in USA (Yeardley et al., 1996), was selected because it is quick and easy to perform, and it is known to be sensitive towards a wide range of chemicals. The principle of this test is that the earthworms are simultaneously exposed to the soil sample spiked with the pesticide, and to a control soil. After a test period of two days the location of the animals is determined. The existing standardized protocol for the Earthworm Avoidance 
Test (ISO, 2006) was modified in terms of test species, substrate and conditions in order to make it suitable for tropical regions. Afterwards, three pesticides relevant for Brazil were studied using the modified test protocol. Tests were performed in Brazil (Embrapa, Manaus) and Germany (ECT, Flörsheim). The results were compared with those determined under temperate conditions as well as in other standardized tests with earthworms. Referring to experiences made with avoidance tests performed under temperate conditions (Hund-Rinke et al., 2003), the work presented here had the following objectives:

- to prove the suitability of the modified test method for the testing of pesticides;

- to compare the results of the avoidance tests performed under tropical and temperate conditions;

- to check whether the modified avoidance test is at least as sensitive as the earthworm acute test and comparable in its sensitivity to the reproduction test.

\section{Material and methods}

\subsection{Test soils}

In this study, two artificial and two natural soils were used (Table 1). Besides the standard test substrate for terrestrial ecotoxicological studies, OECD artificial soil (OECD, 1984), a modified version called tropical artificial soil (TAS) suitable for tropical regions was used (Garcia, 2004). Both artificial soils consisted of $10 \%$ organic matter (peat moss (OECD) or Xaxim fibres, extracted from the trunk of the tree fern Dicksonia sellowiana (TAS)), $20 \% \mathrm{Ka}-$ olinite clay, $50 \%$ industrial quartz sand and up to $0.5 \%$ calcium carbonate in order to adjust the $\mathrm{pH}$ in the optimal range $(6.0 \pm 0.5)$. The dry components of the artificial soils were mixed thoroughly before water was added in order to achieve moisture content of about $35 \%$ dry weight.

In addition, two natural field soils were selected as test substrates: (i) The European natural field soil LUFA 2.2 was selected, which is commercially available (Landwirtschaftliche Untersuchungs- und Forschungsanstalt, Speyer, Germany). It is widely accepted as a standard soil for the performance of ecotoxicological tests with invertebrates (Løkke and Van Gestel, 1998). (ii) A tropical natural soil (TNS), classified as Acrisol, which is representative for Brazil. The chemical and physical properties of TNS are similar to LUFA with the exception of the lower pH (ca. 3.9).

\subsection{Test organisms}

The earthworms from the European strain used in these tests, Eisenia fetida (Lumbricidae), were taken from a breeding culture kept since 1994 at ECT (Germany). For all tests, only adult worms with clitellum with a fresh weight (f.w.) between 250 and $600 \mathrm{mg}$ were used. The animals were bred in a mixture of bark humus and cattle manure as food (1-30 vol.\%) at temperature $15-30{ }^{\circ} \mathrm{C}$ (mean about $20^{\circ} \mathrm{C}$ ) and in continuous darkness. In addition, mass cultures of a "tropical strain" of E. fetida were established at the Embrapa laboratory from samples provided by local earthworm breeders in Manaus, where the cultures were kept in a mixture of TAS with cattle manure $(70: 30, v / v)$ at room temperature $\left(23-30{ }^{\circ} \mathrm{C}\right.$; mean $\left.=26^{\circ} \mathrm{C}\right)$, at a light cycle of $12 \mathrm{~h} / 12 \mathrm{~h}$. All earthworms were fed according to demand, usually once a week, with finely ground cattle manure free of any chemical contamination. The worms selected for the test were acclimatized in the respective soil under test conditions for at least $24 \mathrm{~h}$ before starting the test.

\subsection{Test performance}

The avoidance tests were performed with the European E. fetida in two soils (OECD and LUFA) and with the tropical E. fetida in TAS only. Tests were conducted in 7 concentrations (ranging from 1 to $1000 \mathrm{mg}$ a.i. $/ \mathrm{kg}$ ) for benomyl or carbendazim and in 6 concentrations (ranging from 0.32 to $100 \mathrm{mg}$ a.i. $/ \mathrm{kg}$ ) for lambda-cyhalothrin. Each concentration and the control were tested with 4 replicates. Plastic vessels $(11 \times 15.5 \mathrm{~cm}$ area, $6 \mathrm{~cm}$ height $)$ were filled with soil up to a height of about $4-5 \mathrm{~cm}$ (about $500 \mathrm{~g}$ soil, dry weight). Using a piece of plastic fitted transversally in the vessel, one half of the vessel was filled with contaminated soil, the other filled with control soil, without pesticide treatments. Then the plastic separator was removed and 10 adults of $E$. fetida were placed on the separating line of each test vessel. The vessels were then closed with transparent and perforated lids. The tests were carried out in the dark in incubators at $20 \pm 2{ }^{\circ} \mathrm{C}$ for OECD and LUFA soils, and at $28 \pm 2{ }^{\circ} \mathrm{C}$ for TNS and TAS. The animals were not fed during the test. Soil moisture and $\mathrm{pH}$ were determined according to ISO guidelines. At the end of the test period of $48 \mathrm{~h}$, the control and the contaminated soil sections were carefully separated and the number of earthworms was determined in each section of the vessels. Individuals found between the sections (on the separating line) were counted according to the direction they were moving, i.e., considered in the section where the anterior part of body was. Dead earthworms were classified as escaped animals.

\subsection{Test chemicals}

Benomyl is a broad-spectrum systemic fungicide of the benzimidazole chemical group, which was until quite recently registered for use in more than 50 countries, when it represented about $50 \%$ of the benzimidazole fungicides market worldwide (WHO, 1993a). It was used for the control of a wide range of diseases on more than $70 \mathrm{crops}$, including fruit trees, vegetables and cereals. Benomyl is rapidly converted to carbendazim in the environment with half-lives of $19 \mathrm{~h}$ in soil. It is classified by the World Health Organization (WHO) as an "unlikely hazardous" (U) substance. By the end of 2002, the manufacturer decided to phase out the sale of all benomyl products (US EPA, 2002; EU, 2002). Due to concerns about toxic effects on human health, the substance was also excluded from the list of pesticides registered in Brazil (ANVISA, 2003).

Carbendazim is a systemic benzimidazole fungicide, produced commercially since 1970. It is used to control a broad range of diseases on cereals, fruits and vegetables, as well as in post-harvest food storage, and as a seed pre-planting treatment. Carbendazim is moderately persistent in temperate sandy soils where half-lives of 50-230 days have been found. According to

Table 1

Physico-chemical characterization of artificial and natural soils

\begin{tabular}{|c|c|c|c|c|c|}
\hline Characteristic & Guideline & OECD & TAS & TNS & LUFA \\
\hline $\mathrm{pH}\left(\mathrm{CaCl}_{2}\right)$ & ISO-10390 (1994) & 6.1 & 6.6 & 3.9 & 6.1 \\
\hline $\mathrm{N}$ total $(\%)$ & Embrapa (1997) & 0.11 & 0.15 & 0.13 & 0.19 \\
\hline $\mathrm{C}$ org $(\%)$ & Embrapa (1997) & 3.59 & 3.48 & 2.49 & 2.70 \\
\hline $\mathrm{C} / \mathrm{N}$ ratio & - & 32.6 & 23.2 & 19.2 & 14.2 \\
\hline Density $\left(\mathrm{g} / \mathrm{cm}^{3}\right)$ & ISO-11272 (1998b) & 1.1 & 1.1 & 1.3 & 1.2 \\
\hline WHCmax (\%) & ISO-11268-2 (1998a) & 56.1 & 47.7 & 40.1 & 50.0 \\
\hline
\end{tabular}


WHO, carbendazim is classified as an "unlikely hazardous" (U) substance when in normal use (WHO, 1993b). Recently, carbendazim has been included on Annex I of EU Directive 91/414, but several risk management options have to be put in place (EU, 2006).

Lambda-cyhalothrin is a non-synthetic pyrethroid insecticide and acaricide, developed in 1977. It is highly active against a broad spectrum of pests in public and animal health, but is also employed in agriculture against pests in many crops. Lambda-cyhalothrin has a half-life in soil of 12-16 weeks. According to WHO, lambda-cyhalothrin is classified as "moderately hazardous" (Group II) (WHO, 1990). This compound has been included on Annex I of EU Directive 91/414, meaning that lambda-cyhalothrin is classified as causing no concern to humans or the environment (EU, 2000).

All effect concentrations in this paper are given as nominal values, i.e. as is usual in soil ecotoxicological tests performed according to ISO or OECD guidelines no residue analysis was performed.

\subsection{Data assessment}

In these tests, for each replicate the net response (NR) (expressed as percentage) was calculated as NR $=((C-T) / 10) \times 100$, where $C=$ sum of earthworms observed in control soil; $T=$ sum of earthworms observed in treated soil; $10=$ total number of earthworms per replicate. A positive $(+)$ net response indicates avoidance and a negative net response (-) indicates an attraction to the chemical tested in a given concentration. According to Annex E of ISO guideline 17512 (2006), describing the testing of chemicals, attraction reactions ( $=$ the worms prefer the soil treated with the test chemical) have to be considered as $0 \%$ of avoidance. Prior to analysis, data were tested for homogeneity of variance (Levene's test) and for normal distribution (KolmogorovSmirnov test). The highest no observed effect concentration (NOEC) and lowest observed effect concentration (LOEC) values were determined using ANOVA and Dunnett's test. However, intermediate statistically significant avoidance reactions (which occurred in only two tests (benomyl and carbendazim, both in OECD soil)) were not considered when determining NOEC/ LOEC values. The Student's $t$-test ( $p \leq 0.05$ level) was used for comparing the means of proportions of individuals in the sections (control and treated) of each test vessel, in the chemical treatments (5 concentrations) as well as in the dual-control tests (4 replicates).

The median effective concentration $\left(\mathrm{EC}_{50}\right)$ values and its $95 \%$-confidence limits were determined using Trimmed Spearman-Kärber method (Hamilton et al., 1977). These calculations were based on the mean net response of the four replicates. The statistical methods used here are detailed in Meister and Van den Brink (2000) and Chapman et al. (1996). As statistical software SigmaStat2 and SigmaPlot8 were used.

\section{Results}

\subsection{Validity of the tests}

According to the ISO draft guideline, two validity criteria have to be fulfilled. An avoidance test is valid if:

- $\leq 10 \%$ of the worms died (or escaped). This first criterion was fulfilled in all tests with OECD, TAS and LUFA soils, but since in the tests with TNS the mortality was $>10 \%$, this soil was not considered further;

- if the distribution of the worms is within a range of $50 \pm 10 \%$ between the two halves of a test vessel containing the same type of soil. Such "dual-control" test data establish that, in absence of toxicants, worms do not congregate, but instead distribute themselves fairly randomly with respect to the two halves of the test chambers. That is, they did not display behavior that might be mistaken for avoidance (Yeardley et al., 1996). In order to
Table 2

Effects of benomyl (mg a.i. $/ \mathrm{kg}$ ) on the avoidance behavior of the tropical strain of E. fetida in TAS and on the European strain of E. fetida in OECD and LUFA soils

\begin{tabular}{lccccc}
\hline Soil & EC $_{50}$ & $95 \%-C L$ & & LOEC & NOEC \\
\hline TAS & 54.9 & 43.1 & 69.9 & 31.6 & 10 \\
OECD & 28.2 & 24.5 & 32.4 & 10 & 3.216 \\
LUFA & 1.6 & 1.2 & 2.2 & $<1.0$ & $<1.0$ \\
\hline
\end{tabular}

test the second criterion, the "dual tests" were performed using untreated (or control) soil in each section of the test container in four replicates between the two halves of a test vessel containing the same type of soil. According to this criterion, all avoidance tests with OECD, TAS and LUFA soils were valid, since numbers in the two halves were within the range of $50 \pm 10 \%$.

\subsection{Effects of the fungicide benomyl}

The effects of benomyl are summarized in Table 2. Based on the EC50 values, avoidance reactions were strongest in LUFA and weakest in TAS soils. In TAS soil, a significant $(p \leq 0.01)$ avoidance reaction of tropical earthworms to concentrations of benomyl $\geq 31.6 \mathrm{mg}$ a.i./kg was observed (Fig. 1). In artificial OECD soil the European earthworms reacted significantly ( $p \leq 0.01)$ at concentrations of $\geq 10.0 \mathrm{mg}$ a.i./kg (Fig. 2), while in LUFA soil they showed already significant $(p \leq 0.01)$ avoidance behavior at the lowest concentration $(1.0 \mathrm{mg}$ a.i. $/ \mathrm{kg})$ (Fig. 3). With the exception of the lowest concentration (1.0 mg a.i./kg; (not significant)) in OECD soil, no attraction behavior was observed.

\subsection{Effects of the fungicide carbendazim}

Referring to the EC50 values given in Table 3, the worms reacted most sensitively in LUFA soil but much less in OECD soil. However, in contrast to the tests with the other

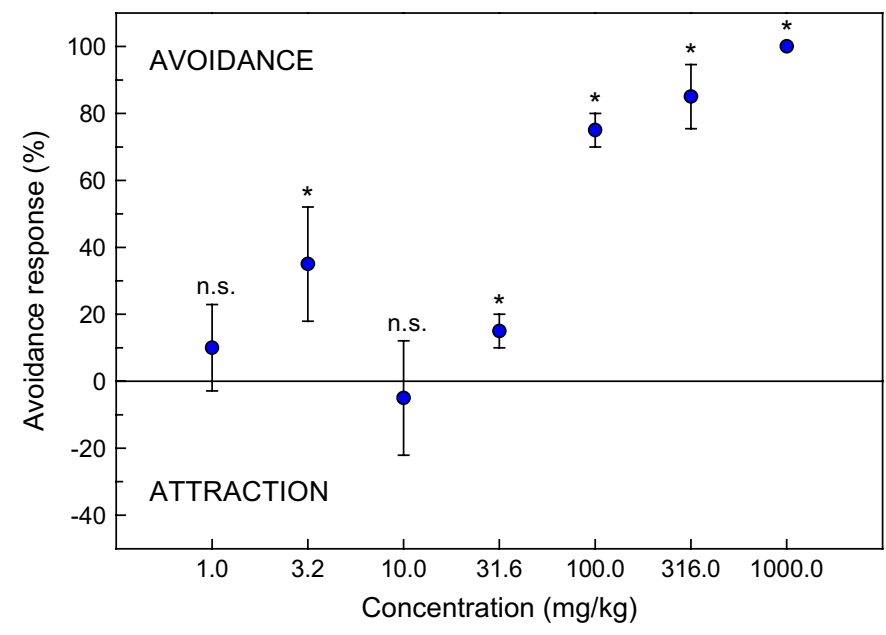

Fig. 1. Avoidance or attraction response of tropical E. fetida to benomyl concentrations in TAS soil (mean net response and standard error bars), (*statistically significant, Student's $t$-test, $p \leq 0.05$; n.s. $=$ not significant). 


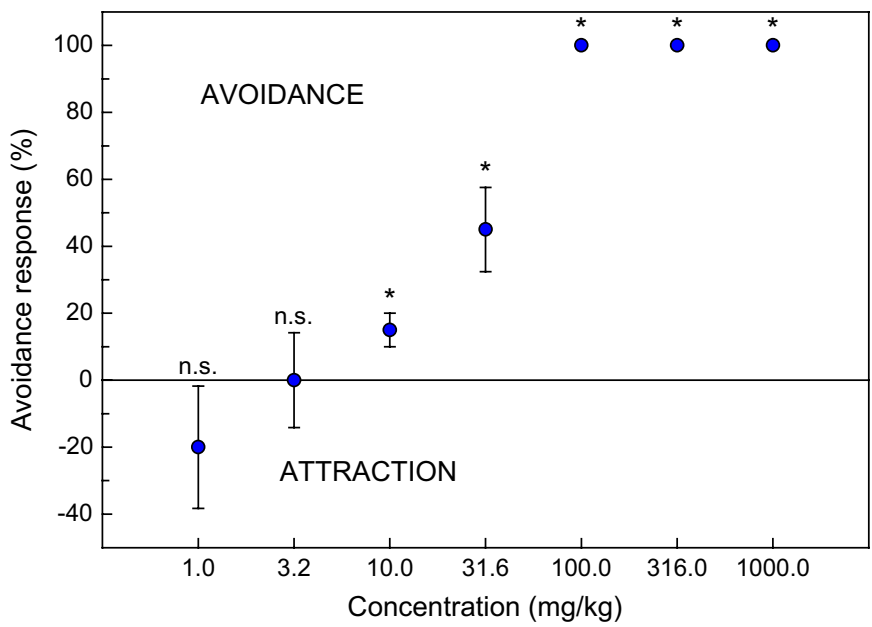

Fig. 2. Avoidance or attraction response of European E. fetida to benomyl concentrations in OECD soil (mean net response and standard error bars), (*statistically significant, Student's $t$-test, $p \leq 0.05$; n.s. $=$ not significant).

two soils the EC50 was difficult to determine because of a vague dose-response relationship at lower concentrations. The results of the test with tropical E. fetida in TAS soil indicate a significant $(p \leq 0.05)$ avoidance behavior of earthworms at concentrations $\geq 1.0 \mathrm{mg}$ a.i./kg (Fig. 4). The same result was found with European earthworms in LUFA soil (significant avoidance behavior at $\geq 1.0 \mathrm{mg}$ a.i./kg; Fig. 6). In artificial OECD soil a significant attraction was observed at the lowest concentration $(1.0 \mathrm{mg}$ a.i. $/ \mathrm{kg})$. Only at the concentration of $100 \mathrm{mg}$ a.i. $/ \mathrm{kg}$ a significant $(p \leq 0.05)$ avoidance reaction occurred, meaning that the NOEC is set at $31.6 \mathrm{mg}$ a.i./kg (Fig. 5). Only in OECD soil was an attraction behavior observed, which was significant at the lowest concentration $(1.0 \mathrm{mg}$ a.i. $/ \mathrm{kg})$.

\subsection{Effects of the insecticide lambda-cyhalothrin}

Strong avoidance behavior was found at very low concentrations in all three soils, almost independently from the effect

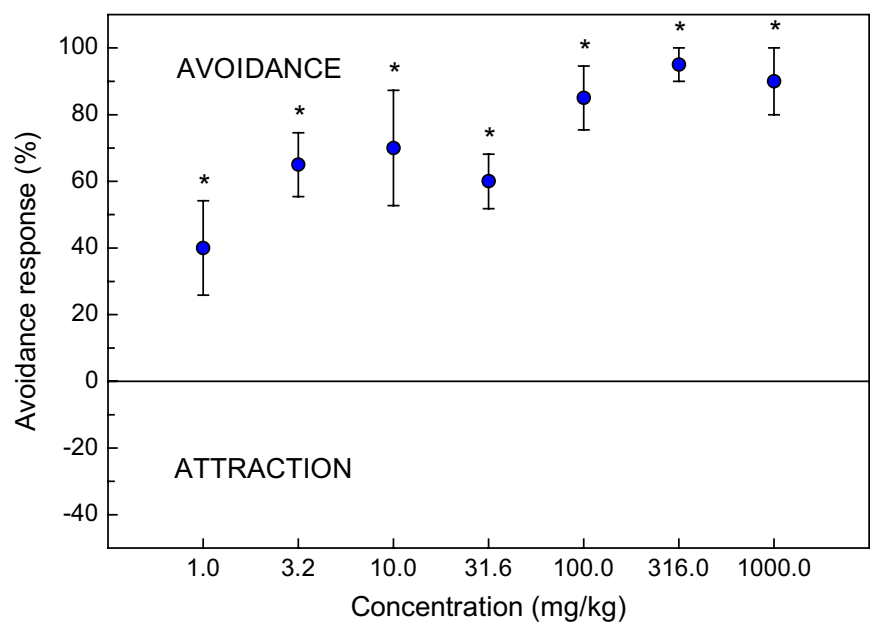

Fig. 3. Avoidance or attraction response of European E. fetida to benomyl concentrations in LUFA soil (mean net response and standard error bars), (*statistically significant, Student's $t$-test, $p \leq 0.05$ ).
Table 3

Effects of carbendazim (mg a.i. $/ \mathrm{kg}$ ) on the avoidance behavior of the tropical strain of E. fetida in TAS and on the European strain of E. fetida in OECD and LUFA soils

\begin{tabular}{lrcrcc}
\hline Soil & EC50 & $95 \%-C L$ & & LOEC & NOEC \\
\hline TAS & 33.3 & 21.7 & 51.2 & $<1.0$ & $<1.0$ \\
OECD & 127.4 & 90.1 & 179.6 & 100 & 31.6 \\
LUFA & 7.1 & 0.7 & 69.2 & $<1.0$ & $<1.0$ \\
\hline
\end{tabular}

values (EC50s or NOECs) used (Table 4). However, the calculated EC50 value $(0.2 \mathrm{mg}$ a.i. $/ \mathrm{kg})$ for TAS soil is outside the tested range. The tropical earthworms showed significant $(p \leq 0.01)$ avoidance behavior towards lambda-cyhalothrin in TAS soil in the lowest concentration $(0.3 \mathrm{mg} / \mathrm{kg})$ (Fig. 7). In artificial OECD soil they significantly $(p \leq 0.01)$ reacted at the concentration of $3.2 \mathrm{mg}$ a.i. $/ \mathrm{kg}$, while in natural LUFA soil the European earthworms showed significant $(p \leq 0.05)$ avoidance behavior in the lowest concentration $(0.3 \mathrm{mg}$ a.i. $/ \mathrm{kg})$ (Figs. 8 and 9). Again, with the exception of OECD soil (non-significant), no attraction reactions were found.

\section{Discussion}

From a technical point of view, the performance of the modified Earthworm Avoidance Test was as easy as in the case of the original version; i.e. changing the substrate, temperature and species did not cause methodological problems. Summarizing the results (Table 5), it could be demonstrated that the sensitivity of E. fetida in avoidance tests is high, but depends on the soil type and the test chemical. In the tests performed with the two fungicides in TAS and OECD artificial soils, using the EC50 values, the earthworms had difficulties to detect and avoid the chemical-contaminated soils. Based on NOEC values, the reaction towards carbendazim occurred at a clearly lower concentration in TAS $(<1.0 \mathrm{mg}$ a.i. $/ \mathrm{kg})$ than in OECD soil $(31.6 \mathrm{mg}$ a.i. $/ \mathrm{kg}$ ). However, when taking the difficult dose-response pattern of carbendazim in OECD

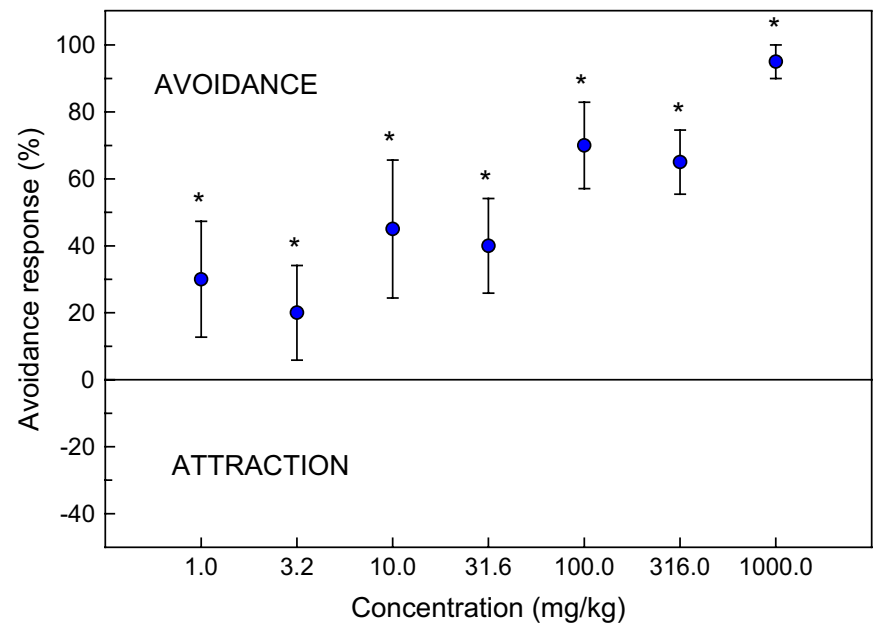

Fig. 4. Avoidance or attraction response of tropical E. fetida to carbendazim concentrations in TAS soil (mean net response and standard error bars), (*statistically significant, Student's $t$-test, $p \leq 0.05$ ). 


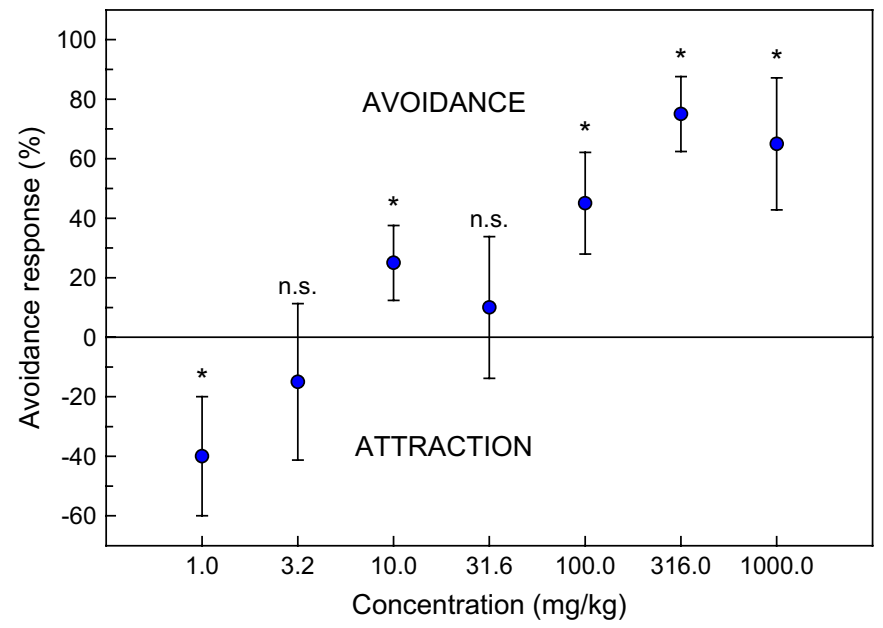

Fig. 5. Avoidance or attraction response of European E. fetida to carbendazim concentrations in OECD soil (mean net response and standard error bars), (*statistically significant, Student's $t$-test, $p \leq 0.05$; n.s. $=$ not significant).

soil into account, this difference may not be very reliable. This impression is also backed up by the observation that only in OECD soil did attraction behavior occur, indicating that this substrate may not be optimal for such tests. In all soils (again, lowest in OECD soil), very low concentrations of lambdacyhalothrin were detected by the worms, indicating a better availability to the earthworm sense organs. In fact, avoidance behavior was, with one exception (benomyl), lowest in OECD soil and, again with one exception (lambda-cyhalothrin), strongest in LUFA soil. The fact that the tests with OECD and LUFA soils were done under temperate (i.e. with European E. fetida at $20^{\circ} \mathrm{C}$ ) and the tests with TAS soil under tropical (i.e. with tropical E. fetida at $28{ }^{\circ} \mathrm{C}$ ) conditions did not have an obvious effect on the results.

Whilst there is no literature data available describing the effects of lambda-cyhalothrin, such avoidance tests have been performed with the two fungicides. According to Loureiro et al. (2005), carbendazim and benomyl cause strong behavioral

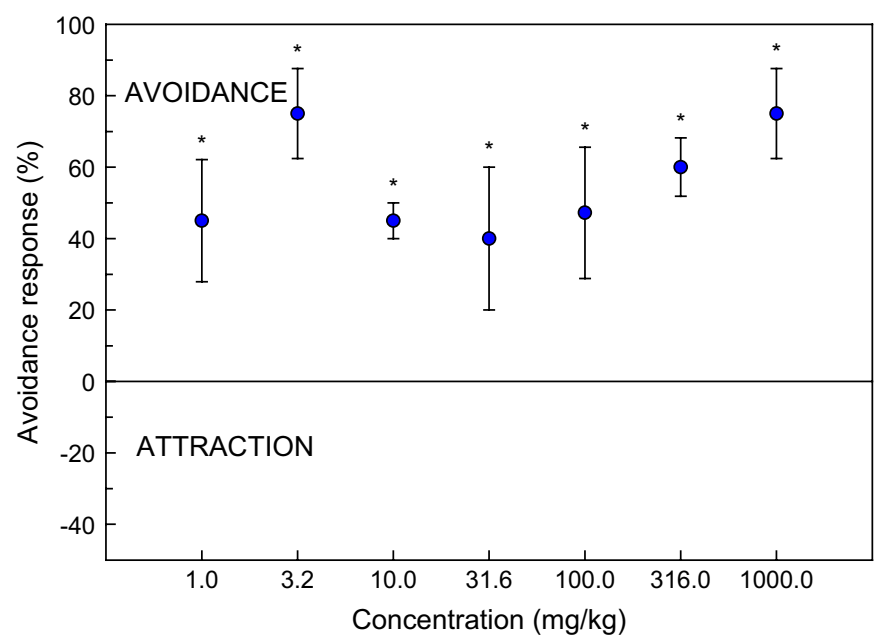

Fig. 6. Avoidance or attraction response of European E. fetida to carbendazim concentrations in LUFA soil (mean net response and standard error bars), (*statistically significant, Student's $t$-test, $p \leq 0.05$ ).
Table 4

Effects of lambda-cyhalothrin (mg a.i./kg) on the avoidance behavior of the tropical strain of E. fetida in TAS and on the European strain of E. fetida in OECD and LUFA soils

\begin{tabular}{llllcc}
\hline Soil & EC $_{50}$ & $95 \%-C L$ & & LOEC & NOEC \\
\hline TAS & 0.2 & 0.0 & 0.8 & $<0.32$ & $<0.32$ \\
OECD & 3.3 & 2.9 & 3.7 & 3.216 & 1.0 \\
LUFA & 0.5 & 0.4 & 0.6 & $<0.32$ & $<0.32$ \\
\hline
\end{tabular}

effects on the species Eisenia andrei in LUFA soil at concentrations starting at about $1 \mathrm{mg}$ a.i./kg (effect values were not determined). In tests with three field soils with different organic matter content $\left(2.9,3.5\right.$ and $12.2 \%$, respectively), the $\mathrm{EC}_{50}$ values of benomyl for $E$. andrei varied between 2.7 and $19.4 \mathrm{mg}$ a.i. $/ \mathrm{kg}$. No correlation between $\mathrm{EC}_{50}$ values and soil organic matter content was found (ESG, 2002). In general, these results are in the same order of magnitude as the data determined in this study.

According to literature, the avoidance behavior of E. fetida is a very sensitive parameter for the detection of low concentrations of pesticides and other chemicals (ISO, 2006). However, there are also examples where the test was not sensitive (e.g., the endogeic lumbricid species Aporrectodea caliginosa did not avoid toxic concentrations of organophosphate insecticides (Hodge et al., 2000)). According to Reinecke et al. (2002), E. fetida was able to detect and avoid low concentrations of the fungicide Mancozeb, but on the contrary showed even a preference for a soil contaminated with lead nitrate. Clearly, the extent of the avoidance behavior depends on the respective chemical to be tested.

The question about the relationship between the quick and easy-to-perform avoidance test and the established, much longer lasting acute (OECD, 1984) and chronic earthworm (ISO, 1998b) tests has been intensively discussed in the literature. The central issue in this discussion is the relative sensitivity of the three tests. Since Garcia (2004) performed all three tests in parallel with the same chemicals, soils and worms, such

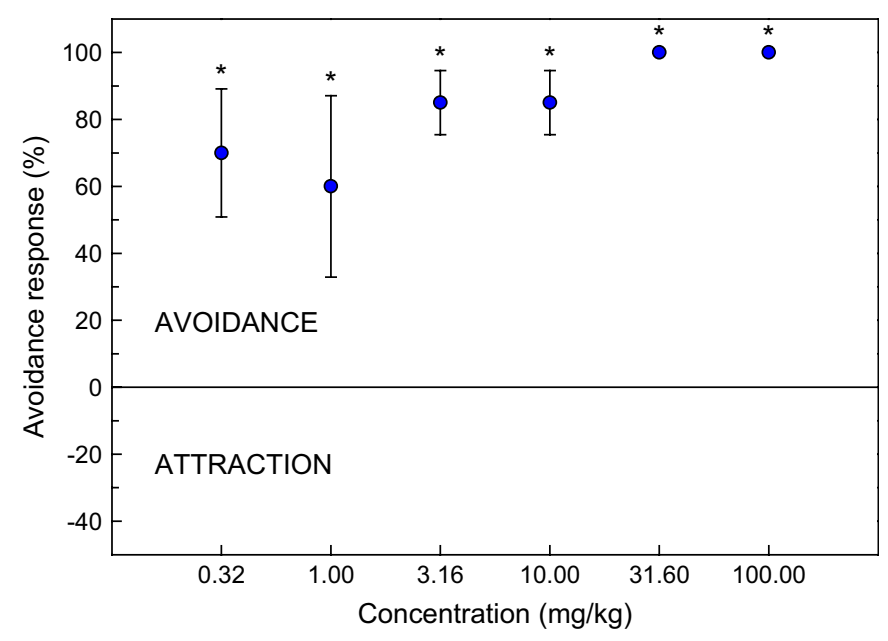

Fig. 7. Avoidance or attraction response of tropical E. fetida to lambdacyhalothrin concentrations in TAS soil (mean net response and standard error bars), (*statistically significant, Student's $t$-test, $p \leq 0.05$ ). 


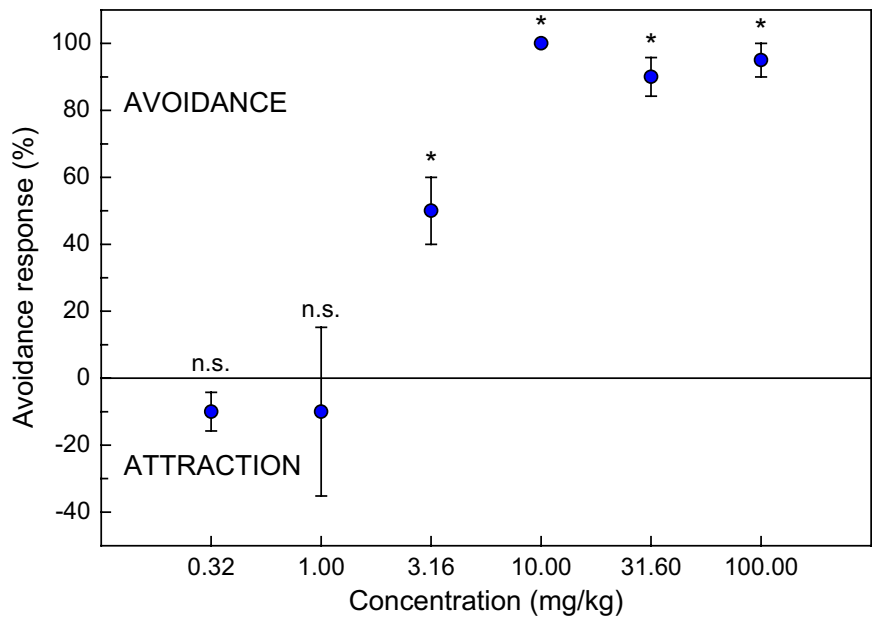

Fig. 8. Avoidance or attraction response of European E. fetida to lambda-cyhalothrin concentrations in OECD soil (mean net response and standard error bars), (*statistically significant, Student's $t$-test, $\quad p \leq 0.05 ; \quad$ n.s. $=$ not significant).

a comparison is directly possible (Table 5). It was observed that the earthworms clearly responded more sensitively in avoidance tests than in acute tests $\left(\mathrm{LC}_{50}\right.$ values were much higher than the $\mathrm{EC}_{50}$ (avoidance) values in six out of nine cases), mainly in TAS and LUFA soils. When comparing the $\mathrm{EC}_{50}$ values from chronic tests with those from avoidance tests, in six cases the reproduction and in three cases (always with lambda-cyhalothrin) the avoidance tests were more sensitive. Based on a NOECchronic/NOECavoidance comparison, there was one similar result while the avoidance test was more sensitive in five out of the remaining eight cases. According to the lowest results from the avoidance tests (here: with LUFA soil), effects of the three test chemicals could occur in the range of few mg a.i./kg soil. In fact, such effects have been found in field studies with benomyl and carbendazim (Van Gestel, 1992), but not with lambda-cyhalothrin (Coulson et al., 1986).

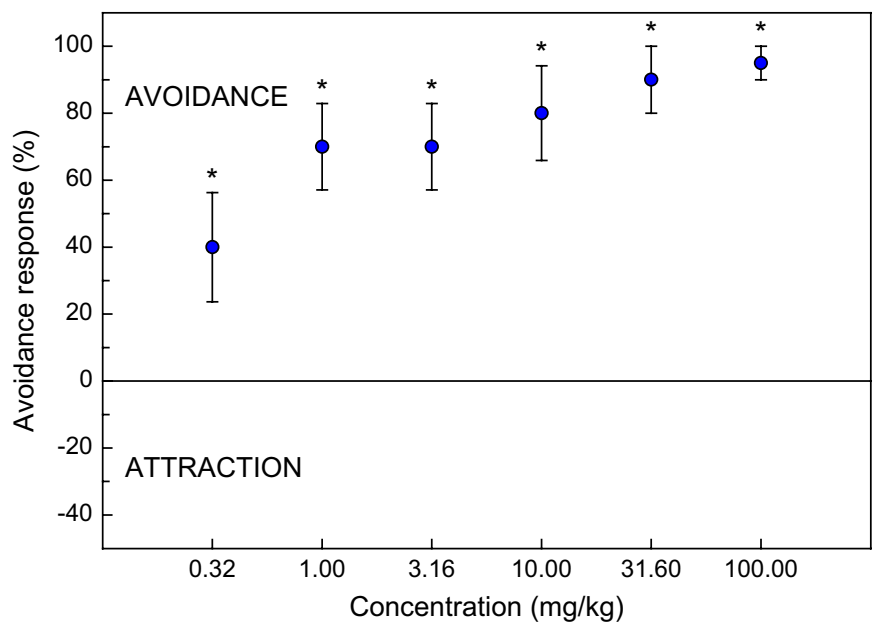

Fig. 9. Avoidance or attraction response of European E. fetida to lambdacyhalothrin concentrations in LUFA soil (mean net response and standard error bars), (*statistically significant, Student's $t$-test, $p \leq 0.05$ ).
Table 5

Comparison of the sensitivity of E. fetida in acute, chronic and avoidance tests (values in $\mathrm{mg}$ a.i./.kg)

\begin{tabular}{|c|c|c|c|c|c|c|c|}
\hline \multirow[t]{2}{*}{ Soil } & \multirow[t]{2}{*}{ Chemical } & \multicolumn{2}{|c|}{ Avoidance test } & \multicolumn{2}{|c|}{ Acute test } & \multicolumn{2}{|c|}{ Chronic test } \\
\hline & & $\mathrm{EC}_{50}$ & NOEC & $\mathrm{LC}_{50}$ & NOEC & $\mathrm{EC}_{50}$ & NOEC \\
\hline \multirow[t]{3}{*}{ TAS } & Benomyl & 54.9 & 10 & 633 & 316 & 3.8 & 3.2 \\
\hline & Carbendazim & 33.3 & $<1.0$ & $>1000$ & 100 & 4.6 & 3.2 \\
\hline & L-cyhalothrin & 0.2 & $<0.3$ & 23.9 & 10 & 7.7 & 6.2 \\
\hline \multirow[t]{3}{*}{ OECD } & Benomyl & 28.2 & 3.2 & 22.0 & n.d. & 1.6 & 1.0 \\
\hline & Carbendazim & 127.4 & 31.6 & 5.8 & 1.9 & 2.7 & 0.1 \\
\hline & L-cyhalothrin & 3.3 & 1.0 & 99.8 & 63.2 & 37.4 & 10.0 \\
\hline \multirow[t]{3}{*}{ LUFA } & Benomyl & 1.6 & $<1.0$ & 14.6 & 2.0 & 1.0 & 0.32 \\
\hline & Carbendazim & 7.1 & $<1.0$ & 4.1 & 1.3 & 0.6 & 0.5 \\
\hline & L-cyhalothrin & 0.5 & $<0.3$ & 139.9 & 31.6 & 44.5 & 3.216 \\
\hline
\end{tabular}

Results from acute and chronic tests are taken from Garcia (2004). Tests in OECD and LUFA were performed with a European strain of E. fetida and in TAS with a tropical strain of this species.

Concerning the question as to data from tests performed under temperate conditions can be used for pesticide risk assessment in tropical regions, the results of the avoidance tests do not give a clear answer. This is caused by the fact that the sensitivity in comparable tests from both regions (i.e. NOEC values from tests in OECD versus those in TAS soils) differs according to the test chemical. In avoidance tests under tropical conditions, the worms reacted more sensitively in TAS soil than in OECD soil when exposed to lambda-cyhalothrin and, in particular, to carbendazim but less sensitively when exposed to benomyl. These differences could be caused by the influence of higher temperature on the degradation or metabolization of these chemicals. It should be noted that when comparing the sensitivity of the three different tests their very different duration (from $46 \mathrm{~h}$ to $56 \mathrm{~d}$ ) has to be taken into account. For example, the lower toxicity of carbendazim in the acute (14 d) and chronic (56 d) tests with TAS soil compared to the tests with OECD soil could be explained by a higher degradation rate under tropical conditions while it will play a less important role in the $48 \mathrm{~h}$ avoidance tests. Independently from these considerations it seems that, when looking at the effect values in LUFA soil compared to those in OECD soil, the use of a field soil (suitable for earthworms) instead of an artificial soil would have a higher effect on the outcome of these tests compared to the "tropical" test modifications performed in this study.

The aim in performing the avoidance tests in natural soils in addition to the standard soils was to obtain toxicity data in ecologically relevant substrates. In temperate regions, the standard soil LUFA 2.2 with a pH ca. 6.0 is a suitable substrate for such tests. A sandy clay loam soil (TNS), typical for tropical Brazil, was selected despite its low $\mathrm{pH}$ of 3.9 , because the other common soil type of this region (Ferralsol) is clearly not feasible for earthworms due to its high clay content and, thus, high density. However, the attempts to test the avoidance behavior with E. fetida in TNS soil were not successful, probably due to its acidity. Therefore, further work is necessary to identify a field soil that occurs in tropical Brazil that at the same time allows the testing of earthworms. 


\section{Conclusion}

The avoidance test is proposed as an easy and quick alternative to the two other tests. In fact, it is clearly more sensitive than the acute test and often at least as sensitive as the chronic one. However, considering the importance of the chronic test (on this level it is decided whether a pesticide is of concern or not (in the former case it has to be tested in the field)) and, therefore, the need for high ecological relevance of the test results, it would be premature to recommend the avoidance tests as a substitute for the chronic test. However, the results obtained in the present study support the idea of using the avoidance test either as a substitute for the acute test or as a screening test for the reproduction test. In any case, more research (in particular broadening the range of test substances with very different modes-of-action and properties) is needed before deciding on the further role of this new test method.

\section{Acknowledgements}

The work presented here is sponsored by the National Council for Scientific and Technological Development (CNPq; Brazil) and by the Federal Ministry of Education and Research (BMBF; Germany). In addition, we would like to thank Hans-Joachim Schallnass for statistical advice.

\section{References}

ANVISA, 2003. Agência Nacional de Vigilância Sanitária. Resolução RE ${ }^{\circ}$ 165: Determina a publicação do "Índice das monografias dos ingredientes ativos de agrotóxicos, domissanitários e preservantes de madeira", cujo emprego encontra-se autorizado conforme descrito na monografia. Diário Oficial da União de 02 de setembro de 2003. Brasília, Brazil.

Chapman, P.F., Crane, M., Wiles, J.A., Noppert, F., McIndoe, E.C. (Eds.), 1996. Asking the Right Questions: Ecotoxicology and Statistics. SETAC Press, Brussels, Belgium.

Coulson, J.M., Collins, I.G., Edwards, P.J., 1986. PP321: effects on earthworms Lumbricidae of repeated annual field applications (Unpublished proprietary report No. RJ0511B, submitted to WHO by ICI).

Embrapa, 1997. Centro Nacional de Pesquisa de Solos. Manual de métodos de análises de solo, 2a ed., Rio de Janeiro. 212p.: il. (EMBRAPA-CNPS. Documentos, 1).

ESG, 2002. Assessment of the biological test methods for terrestrial plants and soil invertebrates: pesticides. Method Development and Applications Section, Environmental Technology Centre. Environment Canada, Ottawa, Ontario, Canada.

EU, 2000. European Union. Commission decision concerning the inclusion of lambda-cyhalothrin in Annex I to Council Directive 91/414/EEC (2000/80/ EC). Official Journal of the European Union, L309: pp. 14-15 Brussels, Belgium.

EU, 2002. European Union. Commission decision concerning the noninclusion of benomyl in Annex I to Council Directive 91/414/EEC and the withdrawal of authorizations for plant protection products containing this active substance (2002/928/EC). Official Journal of the European Union, L322: pp. 53-54, Brussels, Belgium.

EU, 2006. European Union. Commission directive 2006/135/EC amending Council Directive 91/414/EEC to include Carbendazim as active substance. Official Journal of the European Union, L349: pp. 37-41. Brussels, Belgium.

Garcia, M.V., 2004. Effects of pesticides on soil fauna: development of ecotoxicological test methods for tropical regions. Ecology and Development
Series No. 19. Zentrum für Entwicklungsforschung. University of Bonn, Germany, $281 \mathrm{pp}$.

Hamilton, M.A., Russo, R.C., Thurston, R.V., 1977. Trimmed SpearmanKarber method for estimating median lethal concentrations in toxicity bioassays. Environmental Science and Technology 11, 714-719.

Helling, B., Reinecke, S.A., Reinecke, A.J., 2000. Effects of the fungicide copper oxychloride on the growth and reproduction of Eisenia fetida (Oligochaeta). Ecotoxicology and Environmental Safety 46, 108-116.

Hodge, S., Webster, K.M., Booth, L., Hepplethwaite, V., O'Halloran, K., 2000. Non-avoidance of organophosphate insecticides by the earthworm Aporrectodea caliginosa (Lumbricidae). Soil Biology and Biochemistry 32, $425-428$.

Hund-Rinke, K., Achazi, R., Römbke, J., Warnecke, D., 2003. Earthworm avoidance test: results of a laboratory comparison test. JSS - Journal of Soils and Sediments 3, 7-12.

ISO, 1994. International Organization for Standardization. ISO-10390: Soil quality - Determination of $\mathrm{pH}$, Geneve, Switzerland.

ISO, 1998a. International Organization for Standardization. ISO-11268-2: Soil quality - Effects of pollutants on earthworms (Eisenia fetida) Part 2: Method for the determination of effects on reproduction. Geneve, Switzerland.

ISO, 1998b. International Organization for Standardization. ISO-11272: Soil quality - Determination of dry bulk density. Geneve, Switzerland.

ISO, 1998c. International Organization for Standardization. ISO-11277: Soil quality - Determination of particle size distribution in mineral soil material - Method by sieving and sedimentation. Geneve, Switzerland.

ISO, 2006. International Organization for Standardization. Draft ISO-17512: Soil Quality - Avoidance test for evaluating the quality of soils and the toxicity of chemicals. Test with earthworms (Eisenia fetida/andrei). Geneve, Switzerland.

Klein, W., 1989. Mobility of environmental chemicals, including abiotic degradation. In: Bordeau, P., Haines, J.A., Klein, W., Krishna Murti, C.R. (Eds.), Ecotoxicology and Climate SCOPE 38. John Wiley and Sons Ltd, Chichester, UK, pp. 65-78.

Laabs, V., Amelung, W., Pinto, A., Zech, W., 2002. Fate of pesticides in tropical soils of Brazil under field conditions. Journal of Environmental Quality 31, 256-268.

Løkke, H., Van Gestel, C.A.M., 1998. In: Handbook of Soil Invertebrate Toxicity Tests. John Wiley and Sons Ltd, Chichester, UK.

Loureiro, S., Soares, A.M.V.M., Nogueira, J.A., 2005. Terrestrial avoidance behaviour tests as screening tool to assess soil contamination. Environmental Pollution 138, 121-131.

Meister, R., Van den Brink, P.J., 2000. The analysis of laboratory toxicity experiments. In: Sparks, T. (Ed.), Statistics in Ecotoxicology. John Wiley and Sons Ltd, Chichester, UK, pp. 99-118.

OECD, 1984. Organisation for Economic Co-operation and Development: Guideline for Testing of Chemicals No. 207. Earthworm Acute Toxicity Test. Paris, France.

Reinecke, A.J., Maboeta, M.S., Vermeulen, L.A., Reinecke, S.A., 2002. Assessment of lead nitrate and mancozeb toxicity in earthworms using the avoidance response. Bulletin of Environmental Contamination and Toxicology 68, 779-786.

US EPA, 2002. Reregistration Eligibility Decision (RED): Benomyl. United States Environmental Protection Agency. Office of Prevention, Pesticides, and Toxic Substances, Washington, DC, USA.

Van Gestel, C.A.M., 1992. Validation of earthworm toxicity tests by comparison with field studies: a review of benomyl, carbendazim, carbofuran, and carbaryl. Ecotoxicology and Environmental Safety 23, 221-236.

WHO, 1990. Environmental Health Criteria 99: Cyhalothrin. World Health Organization, Geneva, Switzerland.

WHO, 1993a. Environmental Health Criteria 148: Benomyl. World Health Organization, Geneva, Switzerland.

WHO, 1993b. Environmental Health Criteria 149: Carbendazim. World Health Organization, Geneva, Switzerland.

Yeardley, R.B., Lazorchak, J.M., Gast, L.C., 1996. The potential of an earthworm avoidance test for evaluation of hazardous waste sites. Environmental Toxicology and Chemistry 15, 1532-1537. 